\title{
The evolution of insecticide resistance in the peach-potato aphid, Myzus persicae
}

\author{
Alan L. Devonshire ${ }^{1}$, Linda M. Field ${ }^{1}$, Stephen P. Foster ${ }^{1}$, Graham D. Moores ${ }^{1}$, \\ Martin S. Williamson ${ }^{1}$ and R. L. Blackman ${ }^{2}$ \\ ${ }^{1}$ Biological and Ecological Chemistry Department, IACR-Rothamsted, Harpenden, Hertfordshire AL5 27Q, UK \\ ${ }^{2}$ Department of Entomology, The Natural History Museum, London SW7 5BD, UK
}

\begin{abstract}
The peach-potato aphid Myzus persicae (Sulzer) can resist a wide range of insecticides, but until recently (1990) the only mechanism identified was the increased production of carboxylesterases (E4 or FE4), which cause enhanced degradation and sequestration of insecticidal esters. We have now identified two forms of target-site resistance involving changes in the acetylcholinesterase (AChE) and sodium channel $(k d r)$ genes. Biochemical and DNA diagnostic methods can be used to identify all three mechanisms in individual aphids, and thereby establish their spatial distributions and temporal dynamics. Amplified genes underlie the increased production of esterases, but their expression is modulated by DNA methylation. Amplification of the $E 4$ gene is in strong linkage disequilibrium with the kdr mechanism. This may reflect strong insecticidal selection favouring aphids with multiple mechanisms, tight chromosomal linkage and/or the prominence of parthenogenesis in many $M$. persicae populations. The decreased fitness of resistant aphids under winter conditions may be a consequence of the altered sodium-channel gene affecting behaviour and/or the perception of external stimuli.
\end{abstract}

Keywords: aphids; carboxylesterases; chromosomal linkage; gene amplification; target-site resistance

\section{GENETIC CONSIDERATIONS}

Any consideration of the evolution of resistance in peachpotato aphids (Myzus persicae), must take into account their complex life cycle, which can vary according to the different environments in which they occur (Blackman 1974). They have herbaceous summer (secondary) hosts, which include many annual crops such as potatoes, sugar beet, chrysanthemums, tobacco and various brassicas, on which they reproduce by parthenogenesis. Parthenogenetic populations develop as a mixture of clones, with the most favoured ones as potential dominators of the population. They can then overwinter either asexually (through continued parthenogenesis on protected crops, winter weeds or field crops such as oil seed rape) or as sexually-produced eggs on a woody (primary) host. Because $M$. persicae has a strict requirement for peach (Prunus persica) as its primary host, sexual reproduction and meiotic recombination are confined to those areas where this tree is present. The variation in reproductive mode is not only due to the environment but is also dependent on genotype (Blackman 1974). Thus, some clonal lines respond to autumn conditions by producing males and sexual egg-laying females (holocycly), whereas others can only reproduce through continuous parthenogenesis (anholocycly), and yet others are able to produce males but not females (androcycly). Clearly, this will have a large impact on population structure and gene flow.

In addition to showing variation in their reproductive mode, Myzus can display preferences between summer hosts. This can be very marked, to the extent that the aphids become recognizable morphometrically, as with the tobacco-feeding form, which has been classified as a distinct species, M. nicotianae (Blackman 1987). Such segregation would again be expected to restrict gene flow. However, in areas where peach is grown close to tobacco crops, for example in Greece, there is the opportunity for genetic mixing because the two forms retain their ability to interbreed.

A third genetic feature relevant to the evolution of resistance in $M$. persicae is their karyotype. It has long been recognized that a heterozygous translocation between autosomes 1 and 3 is associated with one type of esterase-based resistance (Blackman et al. 1978). The translocation appears to reduce the aphid's ability to reproduce sexually, again having implications for the spread of resistance genes. Aphids with the A 1,3 translocation are widely distributed in warm temperate and tropical regions of the world, and in protected (glasshouse) crops in northern Europe, where they are mostly either anholocyclic or androcyclic.

\section{INSECTICIDE DETOXIFICATION BY ESTERASES}

\section{(a) Biochemistry}

For many years, the only resistance mechanism identified in $M$. persicae was the overproduction of insecticidedetoxifying esterases. This form of resistance was first implicated in the late 1960s by the demonstration that all resistant strains showed an increased ability to hydrolyse the model esterase substrate, 1-naphthyl acetate (Needham \& Sawicki 1971). It was subsequently shown to 
arise from the increased production of one of two forms of esterase, E4 or FE4, that were distinguishable electrophoretically (reviewed by Devonshire 1989). These esterases can account for as much as one per cent of the aphid's total body protein, and give a broad spectrum of resistance to organophosphorus, carbamate and pyrethroid insecticides as a consequence of both ester hydrolysis and sequestration (Devonshire \& Moores 1982). Although FE4 hydrolyses insecticides slightly faster than $\mathrm{E} 4$, the form of esterase overproduced has little effect on the level of resistance (Devonshire et al. 1983).

The biochemical evidence for the role of these esterases in resistance was supported by selection experiments: spraying $M$. persicae populations with pyrethroid insecticides selected strongly for aphids carrying esterase-based resistance to organophosphates and carbamates, and vice versa. This selection has been observed both in the open field (ffrench-Constant et al. 1988a) and in field cages colonized by known initial proportions of susceptible and resistant aphid clones (ffrench-Constant et al. 1987). However, for pyrethroids the contribution of esterases to resistance has recently been shown to be secondary to that conferred by target-site insensitivity, with the two mechanisms being co-selected as a consequence of a strong linkage disequilibrium between them (see below).

\section{(b) Amplification of esterase genes}

The observation that aphid clones with increased amounts of esterase fell into a series with a progressive doubling of enzyme activity, led to the hypothesis that the underlying cause of resistance was amplification of their structural genes, rather than transcriptional control (Devonshire \& Sawicki 1979). This was confirmed in later work, but the phenomenon was shown to be more complex than a simple series of successive duplications (Field et al. 1988). The genes encoding the two esterase forms, E4 and FE4, each span approximately $5 \mathrm{~kb}$ and are very similar (Field et al. 1993). They differ by only nine amino-acid substitutions; and FE4 has an additional 12 amino acids at the $\mathrm{C}$-terminus as a consequence of a mutation that changes the stop codon present in the $E 4$ gene. All clones studied so far have had identical E4 or FE4 genes, including the introns that have been sequenced. This suggests that a single amplification event occurred for each gene, and that they then became dispersed. Likewise, the tobacco-feeding form, $M$. nicotianae, has been shown to have exactly the same amplified genes, indicating that there is gene flow between this and $M$. persicae (Field et al. 1994).

In both $M$. persicae and $M$. nicotianae, amplification of E4 genes always occurs in conjunction with the A 1,3 translocation, whereas aphids that have only the amplified FE4 genes are apparently of normal karyotype. It is very rare to find both forms of the esterase genes amplified in a single individual, pointing to some reproductive isolation between aphids carrying the different genes. The two amplified genes were first seen together in the progeny of laboratory crosses between E4 and FE4 clones (Blackman et al. 1996); and the combination has recently been found in a small number of aphids collected in the field in Greece (Blackman et al. 1998). In the latter case, aphids with both genes amplified have also had the translocation.
The organization of the amplified genes has been studied by analysing large restriction fragments by means of pulsed-field gel electrophoresis (PFGE), which gave very different results for E4 and FE4 genes. Rare-cutting enzymes gave a single DNA fragment of 300-350 kb for amplified $E 4$ genes in $\mathrm{R}_{3}$ aphids, whereas those producing comparable amounts of the FE4 enzyme gave a family of fragments (Field et al. 1996). The complexity of the FE4 pattern precluded detailed analysis, but partial digests of the amplified $E 4$ genes indicated that they were arranged in a tandem array of 12 copies, with the esterase gene being part of a $24 \mathrm{~kb}$ amplicon (Field \& Devonshire 1997). However, recent work (Field et al., unpublished data) has shown that the number of gene copies for both E4 and FE4 genes is higher, and more in line with the level of esterase production.

Further analysis of the E4 and FE4 genes has provided evidence that in susceptible aphids they are in a head-totail arrangement with E4 upstream of FE4, with about $19 \mathrm{~kb}$ of intervening sequence (Field \& Devonshire 1998). Their close similarity suggests a recent duplication event, followed by limited divergence of the two forms. The subsequent amplifications of the E4 or FE4 genes must have involved separate events, each occurring once and then being selected by insecticide treatment and spread by migration (figure 1). The $5^{\prime}$ ends of the genes differ, suggesting that they are regulated in different ways. FE4 appears to have a conventional promoter region, whereas E4 has a CpG island (associated with a $1.7 \mathrm{~kb}$ insertion that is absent from the FE4 gene) that may influence expression through changes in DNA methylation (Field \& Devonshire 1998). This would be in accord with the observation that only E4 genes appear to undergo reversion through changes in transcription (see below). The novel joint (NJ) in the DNA sequence generated during the E4 amplification is just upstream of the transcription start site, and the FE4 joint (FJ) generated by the initial duplication event leading to the divergence of FE4 is only 3 bp away from the NJ. This suggests that this part of the chromosome might be prone to recombination, perhaps as a consequence of the initial duplication. The position of the NJ generated by the FE4 amplification has not yet been identified.

\section{(c) Chromosomal location and inheritance of esterase genes}

Fluorescence in situ hybridization (FISH) has enabled the sites of esterase gene amplification to be identified. The situation is simplest for amplified E4 genes, which, with one exception amongst those clones studied, have always been found at a single locus on the truncated autosome 3 , close to the translocation break-point. In the one exceptional clone, the amplified $E 4$ genes were also found at two other loci on autosomes 2 and 5 (Blackman et al. 1995). In contrast, FE4 genes have been found widely dispersed around the genome, with interclonal variation in the number of loci, some apparently being homozygous and others heterozygous in any one clone (Blackman et al. 1995, 1996). These results are in line with the PFGE data, which indicated a single block of E4 amplicons, but several differently sized groups of FE4 genes (Field et al. 1996). Crossing experiments, some coupled with FISH analysis, have shown that inheritance patterns are consistent with a single heterozygous locus of $E 4$ amplification 


\begin{tabular}{|c|c|c|c|c|}
\hline MEAT & MIV & KIV & IMIV & IIV \\
\hline$E 4$ & FE4 & $F E 4$ & $F E 4$ & $F E 4$ \\
\hline
\end{tabular}

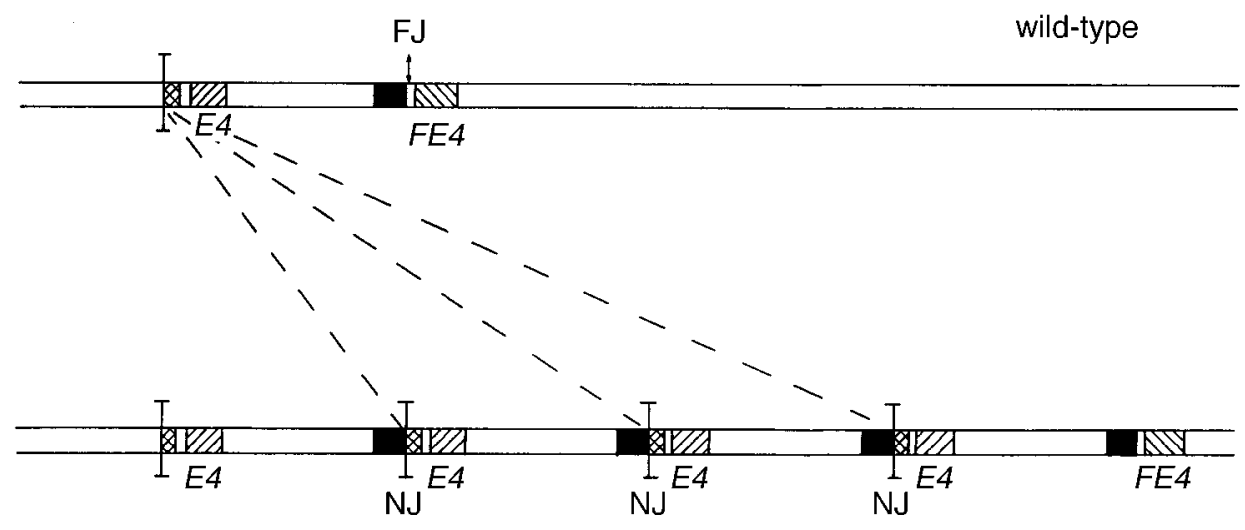

Figure 1. Model for the amplification and organization of E4 and FE4 genes (based on Field \& Devonshire 1998). in $\mathrm{R}_{3}$ clones (Blackman et al. 1978, 1996). In contrast, two- or three-locus models were required for clones showing different degrees of FE4 amplification (Blackman et al. 1996).

Despite their widespread dispersion around the genome, restriction analysis of the amplified genes indicates that all FE4 copies are in the same immediate genetic background, i.e. the amplicon structures are maintained. The same conservation applies to the one aphid clone where the E4 amplicons occur at three loci (Field \& Devonshire 1998). This suggests that in each case an original amplification event occurred recently and the amplicon was then moved, intact, around the genome through rearrangements such as translocations and inversions, or perhaps mediated by transposable elements. The position and sequences around the site of initial duplication (FJ in figure 1) are identical in all of the aphid clones examined, reinforcing the likelihood of a single event that has, subsequently, become widely spread in populations around the world.

\section{(d) Transcriptional control of amplified esterase genes}

Some clonal cultures of aphids with amplified E4, but apparently not FE4, genes lose resistance spontaneously, concomitant with ceasing to over produce the esterase (Sawicki et al. 1980). This 'reversion' phenomenon occurs infrequently and stochastically in laboratory cultures in the absence of selection. However, recent evidence indicates that revertant aphids might be more common in the field than originally considered (L. M. Field and A. L. Devonshire, unpublished data). This loss of esterase-gene expression seems analogous to that seen in cell cultures resistant to cytotoxic drugs, which arises from loss of the amplified genes that confer resistance (Stark 1993). However, in $M$. persicae, revertant aphids retain their full complement of amplified esterase genes, suggesting that decreased transcription is responsible for the loss of enzyme production.

In aphids, the loss of expression was associated with changes in the methylation of the amplified esterase genes (Field et al. 1989); further work demonstrated a tight correlation between the two events (Hick et al. 1996). The amplified genes are expressed when 5-methylcytosine is present in and around the gene, and they are silenced when the methylation is lost in revertants. This positive correlation is contrary to the situation in vertebrates, where methylation is usually associated with gene silencing (Holliday et al. 1996). Revertant aphid clones spontaneously produce a small proportion of offspring with higher esterase levels, which are selected when exposed to insecticides (ffrench-Constant et al. 1988b). This plasticity confers a potential advantage to these aphid clones by enabling them to avoid producing the large amount of esterase protein when it is not needed.

\section{(e) Origin and spread of amplified esterase genes}

The molecular studies of amplified esterase genes, as in mosquitoes (Raymond et al., this issue), points to a small number of isolated mutation events (Field \& Devonshire $1997,1998)$ which then spread rapidly through migration. The mode of aphid reproduction, coupled with their potential for rapid growth as asexual populations, mean that the parthenogenetic offspring of an individual with a marked advantage could become dominant very quickly. Furthermore, the migration of aphids, through both short- and long-distance flight, will lead to the dispersal of resistance genes. However, another way in which insects can become dispersed around the world is as a result of human activity. This has been invoked for mosquitoes, in which their movement through longdistance transport in boats and aircraft appears to have played a part in the rapid spread of resistance genes (Pasteur \& Raymond 1996). Likewise, the international trade in plants and produce offers considerable potential for the widespread distribution of phytophagous insect pests (Frey 1993; Denholm et al., this issue).

\section{TARGET-SITE RESISTANCE}

\section{(a) Insecticide-insensitive acetylcholinesterase}

Insecticide-insensitive acetylcholinesterase (AChE), the target for organophosphorus and carbamate insecticides, is an important resistance mechanism in many insect 
<smiles>Cc1nc(N(C)C)nc(OC(=O)N(C)C)c1C</smiles><smiles>CCOC(=O)CSc1nc(C(C)(C)C)nn1C(=O)N(C)C</smiles>

aldicarb<smiles>CNC(=O)O/N=C/C(C)(C)SC</smiles>
carbofuran

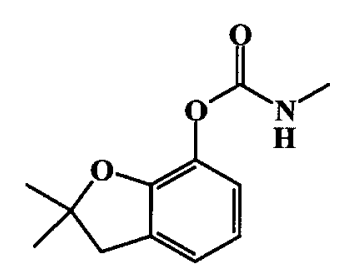

methomyl<smiles>CNC(=O)O/N=C(\C)SC</smiles>

ethiofencarb

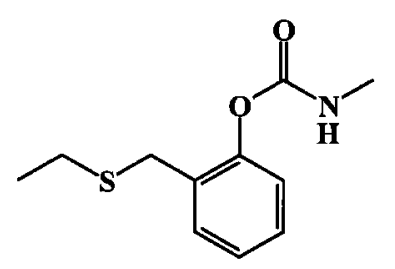

Figure 2. Chemical structures of $\mathcal{N}, \mathcal{N}$-dimethylcarbamates (pirimicarb and triazamate) to which the Myzus AChE is insensitive, and some $\mathcal{N}$-monomethylcarbamates that are unaffected by this resistance mechanism.

species, but was not found in the M. persicae-M. nicotianae complex until 1990 (Moores et al. 1994a). It was first detected in populations from Greece, followed by those from Japan and South America, and has recently shown a northward expansion in its European distribution (Moores et al. 1994b). Aphids with insensitive AChE were first identified in the UK in 1995 from samples which were collected in aerial suction traps but did not cause any control problems in that year. However, in 1996, insensitive AChE occurred commonly in aphids from eastern England (Foster et al. 1998) where there were control failures with pirimicarb, the favoured insecticide for controlling the $M$. persicae that are very resistant $\left(\mathrm{R}_{2}\right.$ and $\mathrm{R}_{3}$ ) owing to esterase overproduction.

The fact that insensitive AChE was only found recently (1990), and only in association with the esterase mechanism (both E4 and FE4), suggests that it evolved after the amplified esterases. The incidence of what appears to be the same $A C h E$ gene alongside both forms of esterase suggests that it originated in a holocyclic individual and then spread through the $M$. persicaeM. nicotianae complex. If it originated as a single mutation event, its introgression into aphids with the A 1,3 translocation (which are anholocyclic or androcyclic) must have been through a female mating with a male from an androcyclic E4-producing clone. The continuous parthenogenetic reproduction of the offspring of such a cross could then have enabled it to be stably maintained in a heterozygous condition, when its phenotypic expression (resistance to pirimicarb) is semi-dominant (Moores et al. 1994b). However, it has also been found in a homozygous condition in combination with amplified $E 4$ as well as $F E 4$, indicating further mating, presumably through E4 males crossing with females of normal karyotype also with the insensitive $A C h E$ gene. In England, aphids with the insensitive $A C h E$ gene have all been red and with amplified E4, whereas in Greece, where FE4 predominates, the insensitive form has been found in both the red and green colour morphs.

The insensitive AChE confers strong resistance specifically to pirimicarb and triazamate, the latter being a novel and otherwise very effective triazole aphicide (Dewar et al. 1994) which also inhibits AChE. Both are $\mathcal{N}, \mathcal{N}$-dimethylcarbamates; there is no insensitivity to a range of organophosphorus compounds nor to aryl and oxime $\mathcal{N}$-monomethylcarbamates (figure 2), suggesting that the bulkier substituents on the carbamate nitrogen are critical for the expression of resistance in this particular species. The insensitivity appears to arise at the inhibition stage, rather than from differential reactivation. Reactivation rates $\left(k_{3}\right.$, measured as described by Devonshire \& Moores (1982)) were too slow to be determined for the sensitive AChE; whilst the insensitive form gave values of only $0.0029 \pm 0.0001 \mathrm{~min}^{-1}$ and $0.00047 \pm 0.00007 \mathrm{~min}^{-1}$ for mono- and dimethylcarbamylated enzyme, respectively.

Although the molecular basis of AChE insensitivity in other species involves one or more point mutations that change amino-acid residues close to the catalytic site of the enzyme (Mutero et al. 1994; Devonshire et al. 1998), the changes in $M$. persicae have not yet been established.

\section{(b) Modified sodium channels (knockdozen resistance or $k d r$ )}

We have recently shown that the esterase-based resistance to pyrethroids in $M$. persicae is of secondary importance compared with a kdr-type mechanism not previously identified in this species (Martinez-Torres et al. 1997, 1998), and that their co-selection appears to have been a consequence of their close association in some clones (Field et al. 1997). Aphids lacking the $\mathrm{kdr}$ mechanism, but with $\mathrm{R}_{3}$ levels of esterase, only show approximately five-fold resistance to deltamethrin. The kdr mechanism alone (as found only in revertant aphids) confers 35-fold resistance and this is enhanced a further 15 -fold by $\mathrm{R}_{3}$ levels of esterase (figure 3). Analysis of aphid clones collected over many years, and reared in the laboratory, indicated that this mechanism had long been present in populations, but was only identified once a molecular diagnostic method became available. The cross-resistance it confers to DDT has since enabled the use of a discriminating dose bioassay for identifying its presence. The $\mathrm{kdr}$ mechanism involves a mutation causing the replacement of a leucine by phenylalanine in the domain IIS6 transmembrane region of the insect para-type sodium-channel gene. This mutation was first identified in house flies (Williamson et al. 1996) and cockroaches (Miyazaki et al. 1996), and the same change has since been found in several insect species including M. persicae (Martinez-Torres et al. 1997; ffrenchConstant et al., this issue).

In UK populations, the kdr mechanism shows strong linkage disequilibrium with the amplification of $E 4$, but not FE4, genes (table 1). This perhaps reflects the almost 


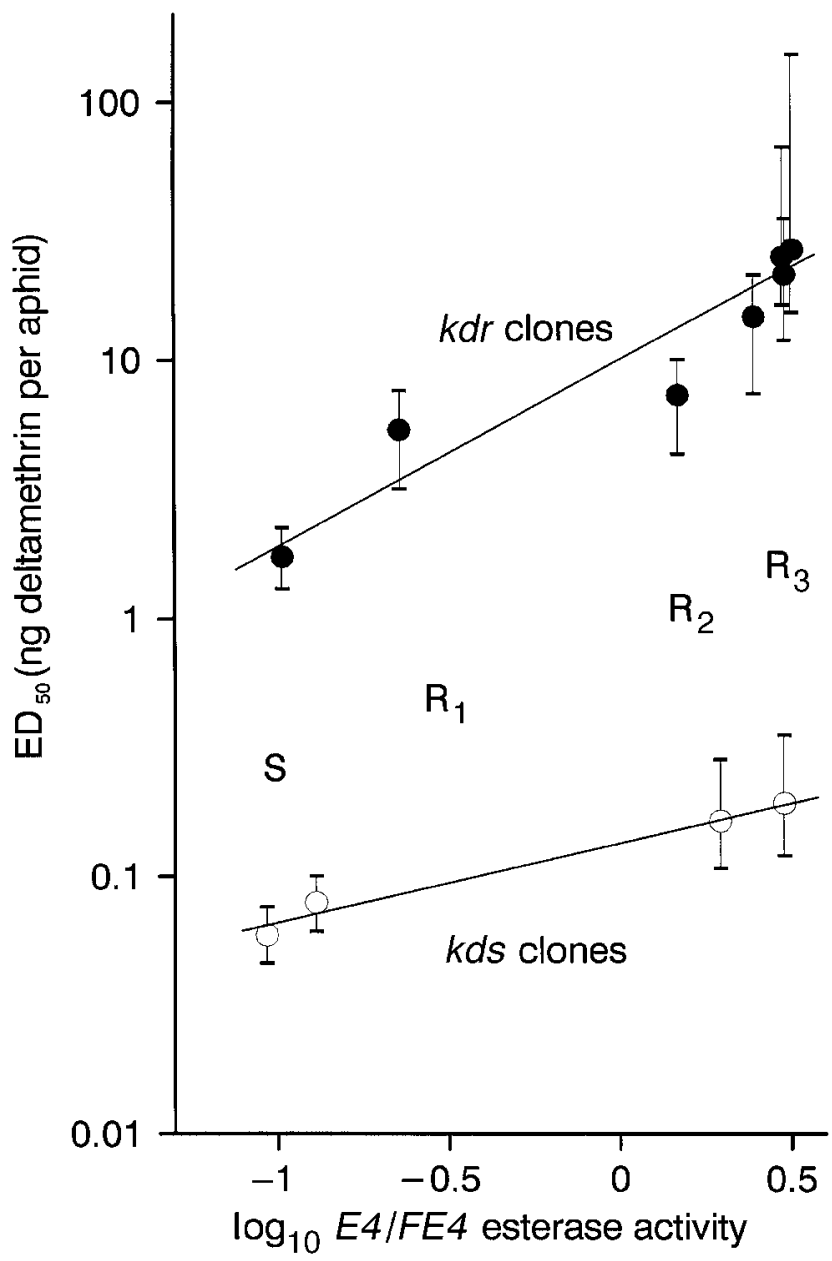

Figure 3. Relationship between toxicity of deltamethrin $\left(\mathrm{ED}_{50}\right)$ and mean esterase activity, measured by immunoassay, in $k d r$ and $k d s$ (i.e. lacking the kdr mechanism) aphid clones. Limits of bars indicate $95 \%$ confidence intervals given by probit analysis. All of the $k d r$ clones have highly amplified $E 4$ genes, but the clone with $\mathrm{S}$ esterase activity is a revertant, and those with $\mathrm{R}_{1}$ and $\mathrm{R}_{2}$ esterase levels appear to be partial revertants, based on analysis of DNA methylation patterns (Field et al. 1989).

exclusive chromosomal location of the amplified E4 genes at a single locus on the truncated chromosome 3 close to the translocation break-point, whereas amplified FE4 genes are more dispersed around the genome (Blackman et al. 1995, 1996, 1998). However, this linkage of the kdr mechanism with E4 gene amplification does not hold fully outside the UK: in a broader survey of aphids from 15 countries, 5 of the 30 clones with amplified E4 genes lacked the $\mathrm{kdr}$ mechanism (Field et al. 1997). It is not known whether the close association of the $\mathrm{E} 4$ and $\mathrm{kdr}$ mechanisms reflects a tight chromosomal linkage. It seems more likely that the $k d r$ mutation first occurred in a single E4-overproducing, translocated aphid, and gave its progeny such a large selective advantage when exposed to a wide variety of insecticides that they survived preferentially and have become widely dispersed as a clone. Following this hypothesis, males from this (androcyclic) clone would then have passed the $k d r$ mutation via the sexual phase to some FE4-overproducing genotypes.
Table 1. Incidence of the $k d r$ mechanism ${ }^{\mathrm{a}}$ in $U K$ aphids with different esterase levels and amplification of $\mathrm{E} 4$ and $\mathrm{FE} 4$ genes

\begin{tabular}{lccccc}
\hline & \multicolumn{4}{c}{ number of clones with: } \\
\cline { 2 - 3 } & \multicolumn{2}{c}{ amplified $E 4$} & & \multicolumn{2}{c}{ amplified $F E 4$} \\
\cline { 2 - 3 } \cline { 5 - 6 } level & $\mathrm{kdr}$ & $\mathrm{kds}^{\mathrm{b}}$ & & $\mathrm{kdr}$ & $\mathrm{kds}$ \\
\hline $\mathrm{R}_{1}$ & 8 & 0 & & 1 & 0 \\
$\mathrm{R}_{2}$ & 26 & 0 & & 3 & 11 \\
$\mathrm{R}_{3}$ & 67 & 0 & & 1 & 1 \\
\hline
\end{tabular}

${ }^{\text {a }}$ Based on a diagnostic bioassay with DDT (Field et al. 1997).

${ }^{\mathrm{b}}$ The corresponding susceptible phenotype is referred to as kds for simplicity.

\section{RELATIVE FITNESS OF SUSCEPTIBLE AND RESISTANT APHIDS}

One of the tenets of resistance management is that, in the absence of insecticides, resistant insects are less 'fit' than their susceptible counterparts. Early studies of $M$. persicae provided evidence for some resistant clones moving less readily between different host species in the laboratory (Eggers-Schumacher 1983). Evidence of a more marked fitness deficit under field conditions began to emerge from the results of regular monitoring of populations throughout and between growing seasons in England (Smith et al. 1990). The proportion of aphids with esterase-based resistance built up during the summer in populations sampled from crops and, more randomly, in the aerial suction traps of the Rothamsted Insect Survey, presumably reflected selection pressure from insecticide use on the various crop hosts of M. persicae. However, their proportions declined over several winters, so that the overall situation remained relatively stable from 1988 to 1995 (Muggleton et al. 1996), suggesting that the more resistant forms were less able to survive the winter climate.

The poorer overwintering performance of E4-over producing resistant aphids, compared with that of susceptible aphids, was clearly demonstrated in four out of nine field experiments over the winters of 1992-3 and 1993-4 (Foster et al. 1996). Several distinct clones from each of the resistance categories, $\mathrm{S}, \mathrm{R}_{1}, \mathrm{R}_{2}, \mathrm{R}_{3}$ and revertants, were colonized as early-instar nymphs on to oilseed rape crops, and their survival determined a month later; one such trial is shown in figure 4 . These predominantly showed a negative correlation between survival and resistance level, with revertants behaving similarly to their $R_{3}$ counterparts (indicating that overproduction of esterase per se is not responsible for the differences observed). The relationship correlated strongly with three meteorological variables: day temperature below $2{ }^{\circ} \mathrm{C}$, mean rainfall and mean wind speed. One of the factors implicated in this maladaptive behaviour was the tendency for the more resistant aphids to remain on deteriorating leaves, whereas the more susceptible clones moved more readily. This was apparent in both field trials and laboratory experiments (Foster $e t$ al. 1997), and would be expected to occur to increase the risk of the resistant aphids being separated from the plant after leaf-fall. Another characteristic was that some resistant 


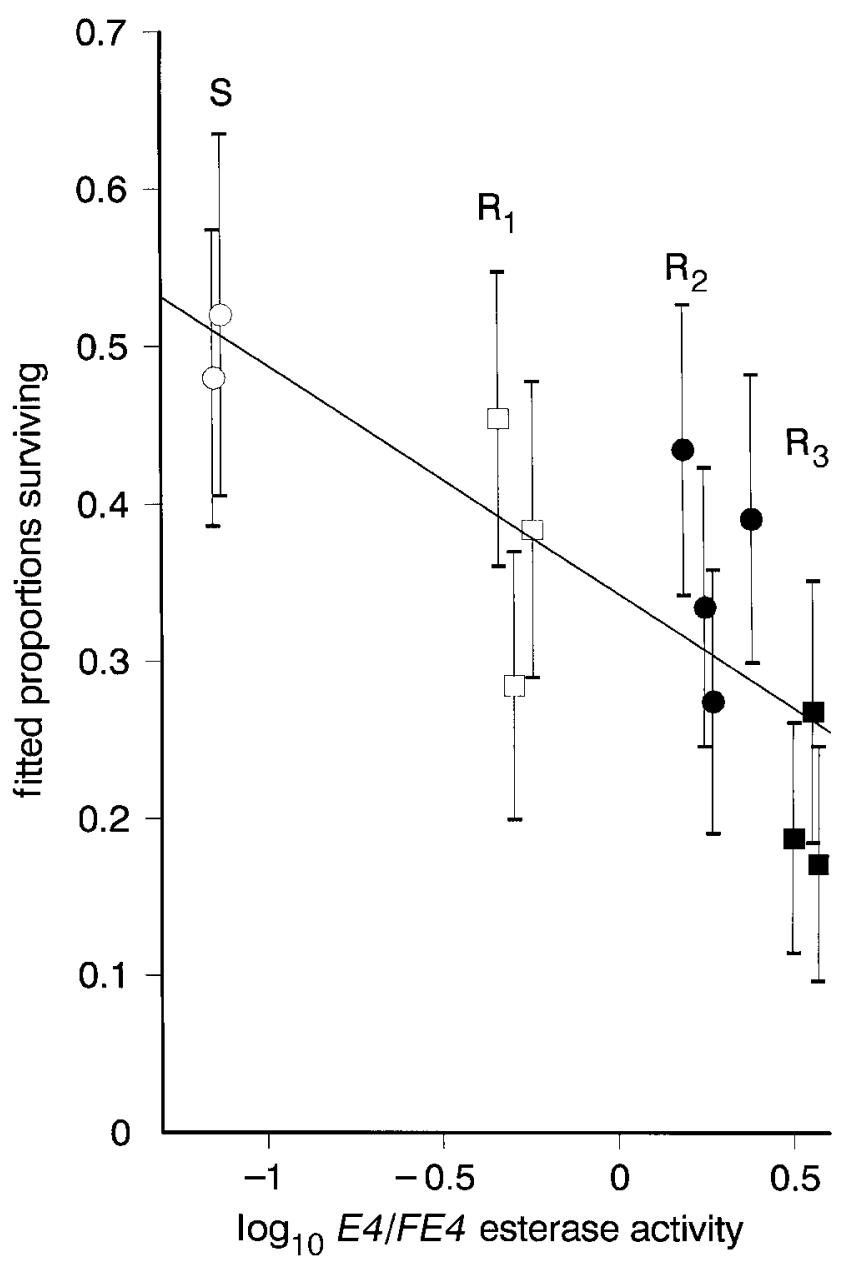

Figure 4. Relationship between esterase activity and the proportion of aphids surviving on oilseed rape crops in the field during a three week period in February 1994 (based on Foster et al. 1996). Symbols: open circles, S clones; open squares, $\mathrm{R}_{1}$ clones; filled circles, $\mathrm{R}_{2}$ clones; filled squares, $\mathrm{R}_{3}$ clones. Limits of bars indicate \pm 1 s.e.

clones of $M$. persicae were shown to be less responsive to their own alarm pheromone (Dawson et al. 1983); and more recent work (Foster et al., unpublished data) has shown this to be so in a wider range of clones.

At the time of these experiments, classification of resistant aphids was based on their esterase content. We now know that the kdr factor commonly occurs in combination with high $\mathrm{E} 4$ production, in UK clones. Because the mutation underlying $\mathrm{kdr}$ is in the sodium-channel gene, this would seem to be a more likely factor mediating the modified behaviour responsible for the reduced overwintering success, e.g. by reducing the sensitivity of the nervous system to stimuli. The smellblind mutant in Drosophila melanogaster provides a precedent for such an effect of a sodium-channel mutation (Lilly et al. 1994).

\section{THE FUTURE}

The way in which resistance will evolve in the future will depend on the pest control measures adopted. Our increasing knowledge of the underlying mechanisms, and the availability of sensitive and rapid diagnostic methods for their identification, opens the way to make rational choices of insecticides to minimize selection pressure in particular circumstances. Increasing pressure to minimize pesticide use is also likely to help reduce the selection for resistance. However, one of the immediate needs is for novel chemicals circumventing, or even exploiting (Hedley et al. 1998), existing mechanisms. The recent introduction of the chloronicotinyl class of aphicides, with its distinctive chemistry and mode of action, holds great promise for addressing this need (Elbert et al. 1990). However, there is already evidence for a low level of resistance to these compounds in some $M$. persicae populations (Devine et al. 1996), and if their promise is to be fulfilled, it will be essential to manage their use carefully from the outset. This issue is addressed by others in this volume.

We thank colleagues in the Resistance Group for their support and useful discussions throughout the work. IACR-Rothamsted receives grant-aided support from the Biotechnology and Biological Sciences Research Council of the United Kingdom.

\section{REFERENCES}

Blackman, R. L. 1974 Life cycle variation of Myzus persicae (Sulz.) (Hom., Aphididae) in different parts of the world, in relation to genotype and environment. Bull. Entomol. Res. 63, 595-607.

Blackman, R. L. 1987 Morphological discrimination of a tobacco-feeding form from Myzus persicae (Sulzer) (Hemiptera: Aphididae), and a key to New World Myzus (Nectarosiphon) species. Bull. Entomol. Res. 77, 713-730.

Blackman, R. L., Takada, H. \& Kawakami, K. 1978 Chromosomal rearrangement involved in insecticide resistance of Myzus persicae. Nature 271, 540-542.

Blackman, R. L., Spence, J. M., Field, L. M. \& Devonshire, A. L. 1995 Chromosomal location of the amplified esterase genes conferring resistance to insecticides in the aphid Myzus persicae. Heredity 75, 297-302.

Blackman, R. L., Spence, J. M., Field, L. M., Javed, N., Devine, G. J. \& Devonshire, A. L. 1996 Inheritance of the amplified esterase genes responsible for insecticide resistance in Myzus persicae (Homoptera: Aphididae). Heredity 77, 154-167.

Blackman, R. L., Spence, J. M., Field, L. M. \& Devonshire, A. L. 1998 Variation in the chromosomal distribution of amplified esterase (FE4) genes in Greek field populations of Myzus persicae (Sulzer). Heredity. (In the press.)

Dawson, G. W., Griffiths, D. G., Pickett, J. A. \& Woodcock, C. M. 1983 Decreased response to alarm pheromone by insecticide-resistant aphids. Naturwissenschaften 70, 254-255.

Devine, G. J., Harling, Z. K., Scarr, A. W. \& Devonshire, A. L. 1996 Lethal and sublethal effects of imidacloprid on nicotinetolerant Myzus nicotianae and Myzus persicae. Pestic. Sci. 48, $57-62$.

Devonshire, A. L. 1989 Insecticide resistance in Myzus persicae: from field to gene and back again. Pestic. Sci. 26, 375-382.

Devonshire, A. L. \& Sawicki, R. M. 1979 Insecticide-resistant Myzus persicae as an example of evolution by gene duplication. Nature 280, 140-141.

Devonshire, A. L. \& Moores, G. D. 1982 A carboxylesterase with broad substrate specificity causes organophosphorus, carbamate and pyrethroid resistance in peach-potato aphids (Myzus persicae). Pestic. Biochem. Physiol. 18, 235-246.

Devonshire, A. L., Moores, G. D. \& Chiang, C. 1983 The biochemistry of insecticide resistance in the peach-potato aphid (Myzus persicae). Pesticide Chemistry (Proc. 5th International Congress of Pesticide Chemistry) 3, 191-196. 
Devonshire, A. L., Byrne, F. J., Moores, G. D. \& Williamson, M. S. 1998 Biochemical and molecular characterisation of insecticide insensitive acetylcholinesterase in resistant insects. In Structure and function of cholinesterases and related proteins (ed. B. P. Doctor, D. M. Quinn, R. L. Rotundo and P. Taylor). New York: Plenum. (In the press.)

Dewar, A. M., Haylock, L. A., Chapman, J., Devine, G. J., Harling, Z. \& Devonshire, A. L. 1994 Effect of triazamate on resistant Myzus persicae on sugar beet under field cages. In Brighton Crop Protection Conference: Pests and Diseases, pp. 407412. Bracknell, UK: BCPC.

Eggers-Schumacher, H. A. 1983 A comparison of the reproductive performance of insecticide-resistant and susceptible clones of Myzus persicae. Entomol. Exp. Appl. 34, 301-307.

Elbert, A., Overbeck, H., Iwaya, K. \& Tsuboi, S. 1990 Imidacloprid, a novel systemic nitromethylene analogue insecticide for crop protection. In Brighton Crop Protection Conference: Pests and Diseases, pp. 21-28. Bracknell, UK: BCPC.

ffrench-Constant, R. H., Devonshire, A. L. \& Clark, S. J. 1987 Differential rate of selection for resistance by carbamate, organophosphorus and combined pyrethroid and organophosphorus insecticides in Myzus persicae (Sulzer) (Hemiptera: Aphididae). Bull. Entomol. Res. 77, 227-238.

ffrench-Constant, R. H., Harrington, R. \& Devonshire, A. L. $1988 a$ Effect of repeated application of insecticides to potatoes on numbers of Myzus persicae (Sulzer) (Hemiptera: Aphididae) and on the frequencies of insecticide resistant variants. Crop Protection 7, 55-61.

ffrench-Constant, R. H., Devonshire, A. L. \& White, R. P. $1988 b$ Spontaneous loss and reselection of resistance in extremely resistant Myzus persicae (Sulzer). Pestic. Biochem. Physiol. 30, 1-10.

Field, L. M. \& Devonshire, A. L. 1997 Structure and organisation of amplicons containing the $\mathrm{E} 4$ esterase genes responsible for insecticide resistance in the aphid Myzus persicae (Sulzer). Biochem. 7. 322, 867-871.

Field, L. M. \& Devonshire, A. L. 1998 Evidence that the E4 and FE4 esterase genes responsible for insecticide resistance in the aphid Myzus persicae (Sulzer) are part of a gene family. Biochem. F. 330, 169-173.

Field, L. M., Devonshire, A. L. \& Forde, B. G. 1988 Molecular evidence that insecticide resistance in peach-potato aphids (Myzus persicae, (Sulz.)) results from amplification of an esterase gene. Biochem. F. 251, 309-312.

Field, L. M., Devonshire, A. L., ffrench-Constant, R. H. \& Forde, B. G. 1989 Changes in DNA methylation are associated with loss of insecticide resistance in the peach-potato aphid Myzus persicae (Sulz.). FEBS Lett. 243, 323-327.

Field, L. M., Williamson, M. S., Moores, G. D. \& Devonshire, A. L. 1993 Cloning and analysis of the esterase genes, conferring insecticide resistance in the peach-potato aphid Myzus persicae (Sulzer). Biochem. 7. 294, 569-574.

Field, L. M., Javed, N., Stribley M. F. \& Devonshire, A. L. 1994 The peach-potato aphid Myzus persicae and the tobacco aphid Myzus nicotianae have the same esterase-based mechanisms of insecticide resistance. Insect Molec. Biol. 3, $143-148$.

Field, L. M., Devonshire, A. L. \& Tyler-Smith, G. 1996 Analysis of amplicons containing the esterase genes responsible for insecticide resistance in the peach-potato aphid Myzus persicae (Sulzer). Biochem. 7. 313, 543-547.

Field, L. M., Anderson, A. P., Denholm, I., Foster, S. P., Harling, Z. K., Javed, N., Martinez-Torres, D., Moores, G. D., Williamson, M. S. \& Devonshire, A. L. 1997 Use of biochemical and DNA diagnostics for characterising multiple mechanisms of insecticide resistance in the peach-potato aphid, Myzus persicae (Sulzer). Pestic. Sci. 51, 283-289.
Foster, S. P., Harrington, R., Devonshire, A. L., Denholm, I. Devine, G. J. \& Kenward, M. G. 1996 Comparative survival of insecticide-susceptible and resistant peachpotato aphids, Myzus persicae (Sulzer) (Hemiptera: Aphididae), in low temperature field trials. Bull. Entomol. Res. 86, 17-27.

Foster, S. P., Harrington, R., Devonshire, A. L., Denholm, I., Clark, S. J. \& Mugglestone, M. A. 1997 Evidence for a possible fitness trade-off between insecticide resistance and the low temperature movement that is essential for survival of UK populations of Myzus persicae (Hemiptera: Aphididae). Bull. Entomol. Res. 87, 573-579.

Foster, S. P., Denholm, I., Harling, Z. K., Moores, G. D. \& Devonshire, A. L. 1998 Intensification of resistance in UK field populations of the peach-potato aphid, Myzus persicae (Homoptera: Aphididae) in 1996. Bull. Entomol. Res. 88, 127-130.

Frey, J. E. 1993 The analysis of athropod pest movement through trade in ornamental plants. In Brighton Crop Protection Conference Monograph no. 54. Plant Health and the European Single Market, pp. 157-165. Bracknell, UK: BCPC.

Hedley, D., Khambay, B. P. S., Hooper, A. M., Thomas R. D. \& Devonshire, A. L. 1998 Proinsecticides effective against insecticide-resistant peach-potato aphids (Myzus persicae (Sulzer)). Pestic. Sci. 53, 201-208.

Hick, C. A., Field, L. M. \& Devonshire, A. L. 1996 Changes in the methylation of amplified esterase DNA during loss and reselection of insecticide resistance in peach-potato aphids, Myzus persicae. Insect. Biochem. Molec. Biol. 26, 41-47.

Holliday, R., Ho, T. \& Paulin, R. 1996 Gene silencing in mammalian cells. In Epigenetic mechanisms of gene regulation, pp. 47-59. New York: Cold Spring Harbor Laboratory.

Lilly, M., Kreber, R., Ganetsky, B. \& Carlson, J. R. 1994 Evidence that the Drosophila olfactory mutant smellblind defines a novel class of sodium channel mutation. Genetics 136, 1087-1096.

Martinez-Torres, D., Devonshire, A. L. \& Williamson, M. S. 1997 Molecular studies of knockdown resistance to pyrethroids: cloning of domain II sodium channel gene sequences from insects. Pestic. Sci. 51, 265-270.

Martinez-Torres, D., Foster, S. P., Field, L. M., Williamson, M. S. \& Devonshire, A. L. 1998 A sodium channel mutation is associated with knockdown resistance (kdr) to DDT and pyrethroids in the peach-potato aphid, Myzus persicae (Sulzer) (Hemiptera: Aphididae). Insect Molec. Biol. (In the press.)

Miyazaki, M., Ohyama, K., Dunlap, D. Y. \& Matsumura, F. 1996 Cloning and sequencing of the para-type sodium channel gene from susceptible and $k d r$-resistant German cockroaches (Blattella germanica) and housefly (Musca domestica). Molec. Gen. Genet. 252, 61-68.

Moores, G. D., Devine, G. J. \& Devonshire, A. L., $1994 a$ Insecticide-insensitive acetylcholinesterase can enhance esterase-based resistance in Myzus persicae and Myzus nicotianae. Pestic. Biochem. Physiol. 49, 114-120.

Moores, G. D., Devine, G. J. \& Devonshire, A. L. $1994 b$ Insecticide resistance due to insensitivie acetylcholinesterase in Myzus persicae and Myzus nicotianae. In Brighton Crop Protection Conference: Pests and Diseases, pp. 413-418. Bracknell, $\mathrm{UK}$ : $\mathrm{BCPC}$.

Muggleton, J., Hockland, S., Thind, B. B., Lane, A. \& Devonshire, A. L. 1996 Long-term stability in the frequency of insecticide resistance in the peach-potato aphid, Myzus persicae, in England. In Brighton Crop Protection Conference: Pests and Diseases, vol. 2, pp. 739-744. Bracknell, UK: BCPC.

Mutero, A., Pralavorio, M., Bride, J.-M \& Fournier, D. 1994 Resistance-associated point mutations in insecticide- 
insensitive acetylcholinesterase. Proc. Natn. Acad. Sci. USA 91, 5922-5926.

Needham, P. H. \& Sawicki, R. M. 1971 Diagnosis of resistance to organophosphorus insecticides in Myzus persicae (Sulz.). Nature 230, 125-126.

Pasteur, N. \& Raymond, M. 1996 Insecticide resistance genes in mosquitoes: their mutations, migration, and selection in field populations. F. Heredity 87, 444-449.

Sawicki, R. M., Devonshire, A. L., Payne, R. W. \& Petzing, S. M. 1980 Stability of insecticide resistance in the peachpotato aphid, Myzus persicae (Sulzer). Pestic. Sci. 11, 33-42.
Smith, S. D. J., Dewar, A. M. \& Devonshire, A. L. 1990 Resistance of Myzus persicae to insecticides applied to sugar beet. In IIRB 53rd Winter Congress, pp. 379-398.

Stark, G. R. 1993 Regulation and mechanisms of mammalian gene amplification. In Gene amplification in mammalian cells (ed. R. E. Hellems), pp. 243-254. New York: Marcel Dekker.

Williamson, M. S., Martinez-Torres, D., Hick, G. A. \& Devonshire, A. L. 1996 Identification of mutations in the housefly para-type sodium channel gene associated with knockdown resistance $(k d r)$ to pyrethroid insecticides. Molec. Gen. Genet. 252, 51-60. 